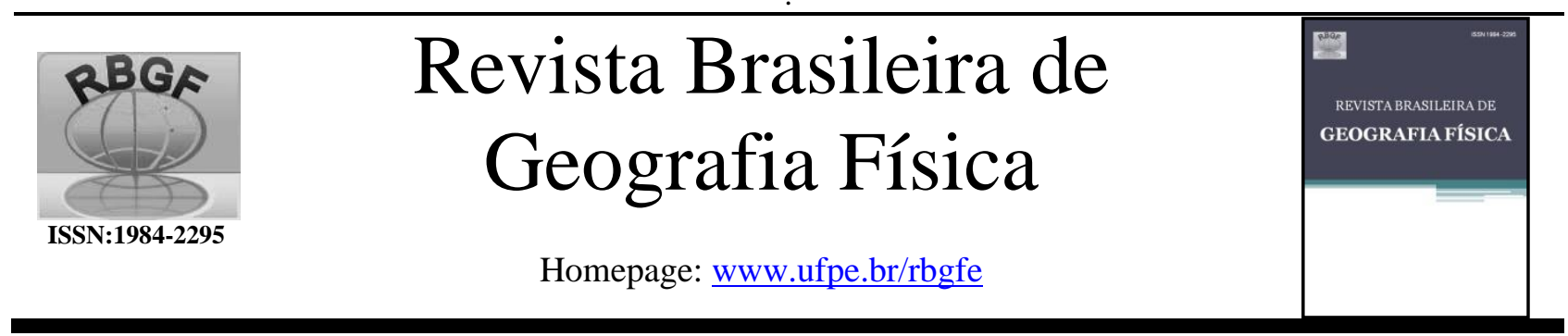

\title{
Deteç̧ão de Construções em Imagens RapidEye com Uso do Operador Brec Urban Focus: Estudo Aplicado a Zona de Amortecimento da Esecae DF
}

\author{
Marcos Roberto Farias Ferreira ${ }^{1}$, Valdir Adilson Steinke ${ }^{2}$, Edilson de Souza Bias ${ }^{3}$, Neio Lúcio de Oliveira Campos ${ }^{4}$ \\ ${ }^{1}$ Ms. em Geografia, Analista de Atividades do Meio Ambiente, Diretoria de Avaliação da Qualidade Ambiental, Instituto Brasília Ambiental, SEPN \\ 511, Bloco C , Edifício Bittar, CEP 70.750-543, Brasília, Distrito Federal. (61) 3214-5653. marcfafer@ gmail.com (autor correspondente). ${ }^{2}$ Dr. em \\ Ecologia, Professor Adjunto, Departamento de Geografia, Universidade de Brasília, Campus Darcy Ribeiro, CEP 70910-900, Brasília, Distrito Federal. \\ (61) 3107-7264. valdirrs @ unb.br ${ }^{3}$ Dr. em Geografia, Professor Associado, Instituto de Geociências, Universidade de Brasília, Campus Darcy Ribeiro, \\ CEP 70910-900, Brasília, Distrito Federal. (61) 3107-7006. edbias @ gmail.com. ${ }^{4}$ Dr. em Planejamento Urbano e Regional, Professor Adjunto, , \\ Departamento de Geografia, Universidade de Brasília, Campus Darcy Ribeiro, CEP 70910-900, Brasília, Distrito Federal. (61) $3107-7264$. \\ neiocamp@unb.br.
}

Artigo recebido em 03/07/2018 e aceito em 14/12/2018

\section{R E S U M O}

A Estação Ecológica de Águas Emendadas é de fundamental importância para a preservação de recursos hídricos, visto que tem relação direta com as bacias dos rios Maranhão e São Bartolomeu, sendo o divisor de duas grandes bacias nacionais, do Rio Paraná e dos rios Tocantins e Araguaia. Sua zona de amortecimento foi formalmente estabelecida pelo plano de manejo elaborado em março de 2009. Conhecer os usos antrópicos existentes nessa zona de amortecimento é um meio para a mitigação dos impactos diretos na unidade que decorrem da ação antrópica. Há nessa localidade, após a formalização do plano de manejo, o surgimento de loteamentos, visível em imagens de satélites. A validação de métodos rápidos e automatizados para a detecção de construções nessa área é de fundamental importância para a fiscalização e o controle de ocupações irregulares. Este trabalho permitiu a identificação de construções e loteamentos na zona de amortecimento a partir de procedimentos que integraram imagens RapidEye do ano 2014 e o uso do operador brec urban focus presente no software InterIMAGE. A qualidade do resultado obtido foi avaliada pelo índice Kappa e pela Exatidão Global da amostra, calculados com uso do aplicativo AVACIM (PRINA, 2014), a partir de pontos gerados por meio da ferramenta hawth's tools, separados em duas classes: loteamento/construções e não loteamento, e conferidos com aerofotos de resolução espacial de $24 \mathrm{~cm}$, com índice Kappa de 0,72, e Exatidão Global da amostra de 0,86.

Palavras-chave: brec urban focus, índice Kappa, GEOBIA, zona de amortecimento.

\section{Detection of buildings in RapidEye Images Using the Brec Urban Focus Operator: Study Applied to the Buffer Zone of Esecae DF}

\begin{abstract}
A B S T R A C T
The Ecological Station of Águas Emendadas has fundamental importance for the preservation of water resources because it is directly related to the basins of Maranhão River and St. Bartholomew River, and it is the divisor of two large national basins, the Paraná River and the Tocantins/Araguaia rivers, its mitigation buffer zone was formally established by the management plan prepared in march 2009. Knowing the existing anthropic uses in this area is a mean to mitigate the direct impacts on the unit that arise from human action. There is, after the formalization of the management plan, the emergence of allotments, visible on satellite images. The validation of fast and automated methods for the detection of buildings in this area is of fundamental importance for the inspection and control of irregular occupations. This work aims to identify buildings in the buffer zone based on procedures that integrated RapidEye images from the year 2014 and the use of the brec urban focus operator present in the InterIMAGE software. The quality of the obtained result was evaluated by the Kappa index and the Global Accuracy of the sample, calculated using the AVACIM (PRINA, 2014), using points generated through the tool hawth's tools, separated into two classes: allotment / constructions and not allotment, and conferred with $24 \mathrm{~cm}$ spatial resolution aerophotos. The value for the Kappa index was 0.72, and the Global Accuracy of the sample was 0.86 .
\end{abstract}

Keywords: brec urban focus, Kappa index, GEOBIA, buffer zone. 


\section{Introdução}

O uso e ocupação da terra no território do Distrito Federal tem se dado, pela transformação territorial de áreas rurais em áreas urbanas e de usos agrícolas em usos urbanos, em um processo acelerado de urbanização marcado pela periferização com segregação socioespacial, e com tendência à conurbação.

O entorno da Estação Ecológica de Águas Emendadas - ESECAE-DF está inserido nessa lógica de expansão urbana, sendo alvo de uma intensa antropização, e notadamente nas zonas sul e leste da referida Unidade de Conservação da Natureza.

A área preservada pela ESECAE DF é de fundamental importância para a preservação de recursos hídricos visto que tem relação direta com as bacias dos rios Maranhão e São Bartolomeu, além de ser o divisor de duas grandes bacias nacionais, do Rio Paraná e dos rios Tocantins e Araguaia. Sua zona de amortecimento foi formalmente estabelecida pelo plano de manejo e abrange uma área de 40.923 ha no seu entorno.

A retirada da vegetação superficial e posterior conversão em outro tipo de cobertura desencadeia uma série de alterações significativas no meio físico e no ciclo da água (Andrade e Lourenço, 2016).

A identificação dos tipos de cobertura do solo fornece informação básica para a geração de mapas temáticos e estabelece um marco inicial para o monitoramento de atividades (Gomez, 2016).

Com o avanço gradual e a disponibilidade de imagens de sensoriamento remoto de alta resolução temporal e espacial, as possibilidades de monitoramento de problemas urbanos com melhor precisão tornaram-se mais promissoras (RAFIU et al, 2018).

As áreas urbanas são de natureza muito complexa, entretanto, com base em algumas características gerais, os especialistas tentam dividir o ecossistema urbano em três constituintes principais: vegetação, área construída (superfícies impermeáveis) e solo descoberto (Nagne et al, 2018).

Assim sendo, analisar o processo de urbanização, com a detecção de loteamentos e construções, bem como a utilização de métodos rápidos e automatizados que proporcionem a detecção desses tipos de feições antrópicas são de fundamental importância para a fiscalização e o controle de ocupações irregulares na área abrangida pela zona de amortecimento, constituindo então ferramentas de apoio para a gestão do território.

Dessa forma, este trabalho tem por finalidade identificar construções no território, tendo como área de estudo a zona de amortecimento da ESECAE DF. Para tal, utilizou o operador brec urban focus, ferramenta de GEOBIA presente no SIG InterIMAGE.

Trata-se de uma temática atual haja vista a estratégia de remoção de construções irregulares capitaneada pela Agência de Fiscalização do Distrito Federal - AGEFIS na atual gestão do Governo do Distrito Federal.

A Importância da GEOBIA em integração S.R. e SIG para estudos embasados em Geoprocessamento

A evolução do sensoriamento remoto proporcionou o desenvolvimento de uma variedade de técnicas de análises espaciais. As quais envolvem interpretação de imagens de satélites mediante técnicas de fotointerpretação, processamento digital dessas imagens, classificações supervisionadas e não supervisionadas, desenvolvimentos de algoritmos para automação de procedimentos e análise geográfica de imagens baseada em objetos (geobia). Esse desenvolvimento tem se dado em virtude da necessidade de conversão dos dados presentes nas imagens em informação objetiva, que tem se dado pela utilização de sistemas de sensoriamento remoto e pela integração de dados com sistemas de informação geográfica (SIGs).

Ao ordenar ou produzir suas imagens de espaço, suas figurações espaciais, seus mapas, suas geografias ou outros produtos simbólicos, os seres humanos ordenavam e ainda ordenam a si mesmos (Katuta, 2013).

Kerski (2015, p. 15) ressalta que as sociedades estão em um rápido movimento em direção a uma era em que praticamente tudo na vida cotidiana será passível de ser localizado em um mapa.

Mais recentemente tem-se desenvolvido a técnica de análise de imagens baseada em objetos, do inglês object based image analysis - OBIA, que também tem sido difundida pelo uso da expressão análise geoespacial de imagens baseada em objetos, do inglês geospatial object based image analysis - GEOBIA, ou simplesmente pelos termos OBIA e GEOBIA os quais têm sido adotados como sinônimos pela comunidade científica.

Enquanto a abordagem baseada no pixel seja fundamentada nas informações de cada pixel, a OBIA é baseada em informações de um conjunto de pixels semelhantes chamados objetos ou objetos da imagem (Dolui, 2018). 
Os objetos são visualmente perceptíveis na imagem, tipicamente representados por aglomerados de pixels vizinhos semelhantes que compartilham um referente comum, ou significado, como os pixels que compõem uma coroa de árvore, ou as culturas em um campo (Chen et al., 2018).

Segundo Ma et al (2017, p. 278), a orientação a objetos surgiu para atender aos desafios de identificação de classes em imagens de alta resolução. Uma vez que, de acordo com Ming et al (2015, p. 28), a classificação de imagens com base no comportamento espectral pode gerar erros de classificação.

Segundo Chen e Weng (2018, p. 155), imagens de alta resolução são aquelas com resolução espacial de $5 \mathrm{~m}$ ou menos, e o sensoriamento remoto de alta resolução é uma solução viável para o monitoramento e análise da dinâmica de paisagens e sua representação em escalas detalhadas.

Mais que uma abordagem experimental, a GEOBIA é um conjunto de ferramentas adaptáveis e bem testadas que analistas podem aplicar com foco na rápida conversão de dados em informação (O’neill-Dunne et al., 2014).

A GEOBIA oferece possibilidades para situações em que as propriedades espectrais não são únicas, mas quando as formas e as relações de vizinhança são distintas (Blaschke et al., 2014).

A técnica OBIA leva em consideração as formas, texturas e informações espectrais (Sibaruddin, 2018). Permite ao usuário integrar ao processo de análise uma gama de características das feições, tais como: forma, tonalidade, tamanho, padrão, associação e textura (Blaschke et al., 2014).

De acordo com Li et al (2015, p. 1592), atualmente é comumente aceito que o uso simultâneo de informações espectrais e informações espaciais promovem ganhos de performance na aplicação de técnicas de classificação.

A análise orientada a objetos toma por base a segmentação da imagem. A partir da segmentação são delimitadas regiões da imagem segundo critérios de homogeneidade, tais como área e similaridade do comportamento espectral dos pixels, permitindo então o agrupamento dos pixels com características semelhantes em segmentos específicos.

Os segmentos possuem informações espectrais, tais como: mínimo, media e desvio padrão. Mas, além disso, apresentam também uma gama de atributos adicionais que são úteis ao processo de análise e de classificação das imagens, são eles: forma, relações de vizinhança, limites, fronteiras, textura, contexto e compacidade.

Essa integração entre SIG e sensoriamento remoto, incrementada pela GEOBIA, tem se mostrado essencial para a geração de dados atuais e para a atualização de dados já existentes, bem como a geração de informação gráfica na forma de mapas, em função de necessidades de planejamento e gerenciamento, os quais demandam informações espaciais constantemente atualizadas.

\section{Área de estudo}

A área de estudo é caracterizada pela Zona de Amortecimento da Estação Ecológica de Águas Emendadas no Distrito Federal, na porção nordeste do território dessa unidade federativa, com uma área de 40.923 há, a qual foi definida Plano de Manejo da referida Unidade de Conservação, Figura 1. 


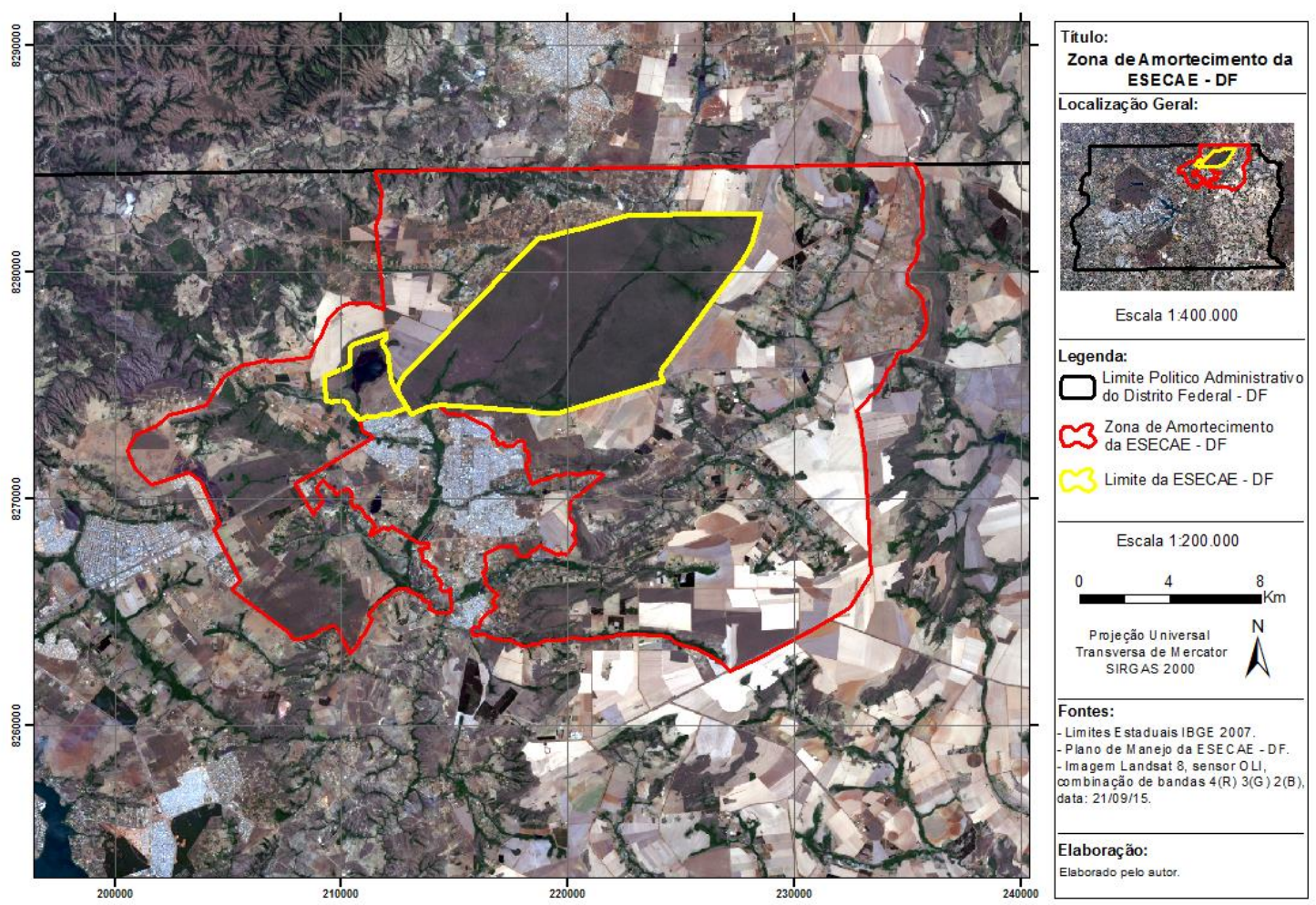

Figura 1: Área de Estudo.

O plano de manejo constitui um instrumento de gestão da unidade de conservação da natureza e trata do seu zoneamento, voltado para a preservação dos seus atributos naturais, sejam eles geomorfológicos, geológicos, hídricos, fitogeográficos, assim como dos culturais, e também da fauna e da flora presentes na área protegida. Podendo agregar à gestão da unidade de conservação da natureza, o estabelecimento de uma zona de amortecimento no entorno da área protegida, como ocorreu com o plano de manejo da ESECAE DF, na qual também constam recomendações específicas de uso com vistas à mitigação de impactos, na área protegida, decorrentes da ação antrópica.

De acordo com Leite et al (2018, p. 28) o plano de manejo é um importante documento técnico que representa cada peculiaridade da área protegida.

O plano de manejo é entendido como um documento técnico baseado em critérios e objetivos que defendem o uso e proteção de uma unidade de conservação (Oliveira et al, 2017).

Ele deve representar o diagnóstico e planejamento para o futuro, além de estabelecer medidas protetoras para a área, controle das atividades exercidas, controle de capacidade de carga e elaboração para diretrizes acerca do uso público, dentre outros (Pires e Rugine, 2018).

Cury $(2013$, p. 46, 47) argumenta que o zoneamento trata do ordenamento territorial da unidade de conservação da natureza e que as regras de uso e de não uso são pautadas pela sua vocação e pelos seus atributos socioambientais.

Um exemplo da atualidade e relevância da ESECAE DF e sua Zona de Amortecimento para o planejamento é o mapa de combate à grilagem e ocupações irregulares elaborado pelo do Governo do Distrito Federal, o qual indica uma área extensa na Zona de Amortecimento da referida unidade de conservação da natureza para o combate à grilagem e ocupações irregulares, conforme representado na Figura 2. 

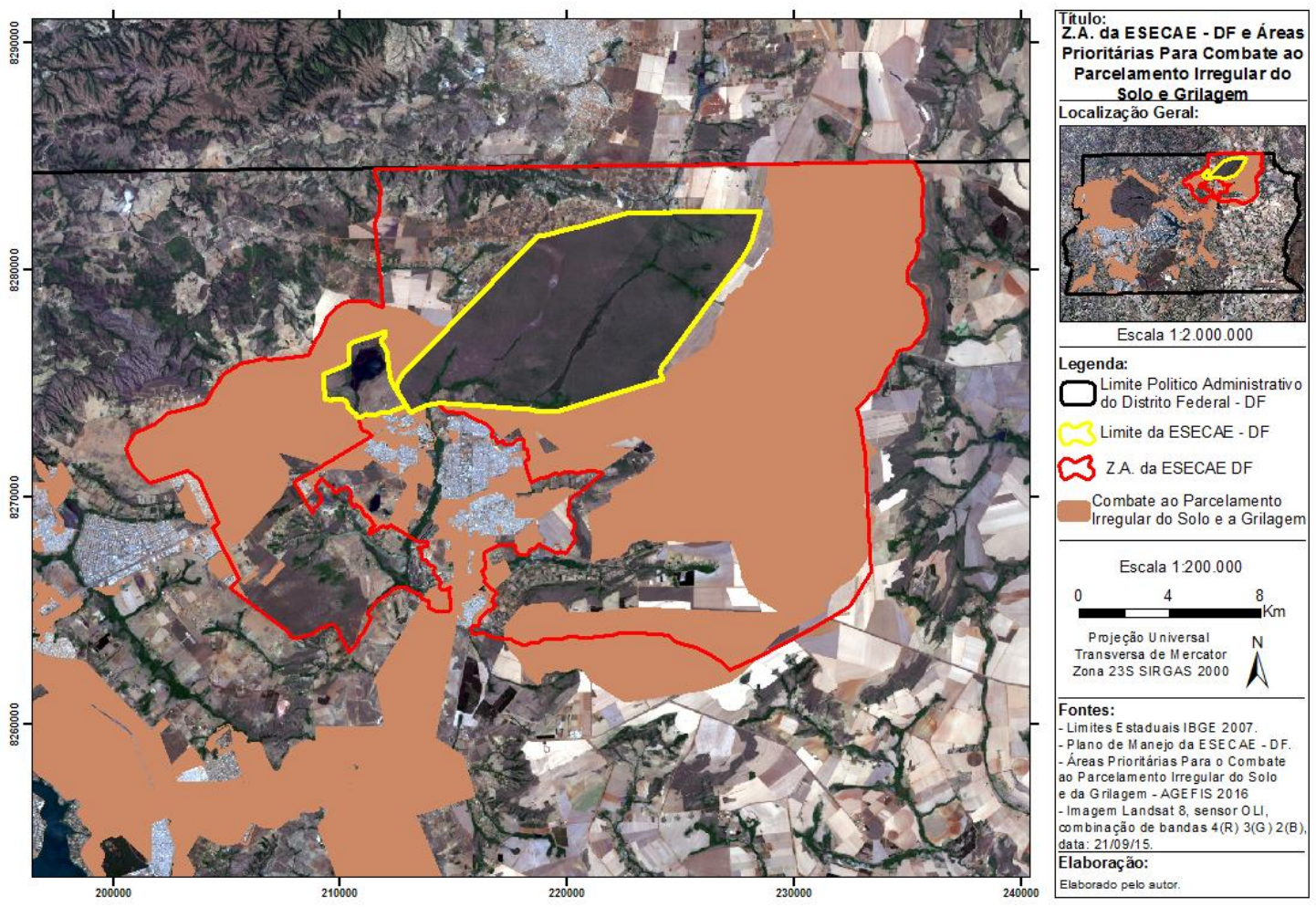

Figura 2: Áreas Prioritárias para Combate ao Parcelamento Irregular do Solo.

Além disso, a área é banhada pelas bacias hidrográficas dos rios Maranhão, São
Bartolomeu e Rio preto, representadas na Figura 3.
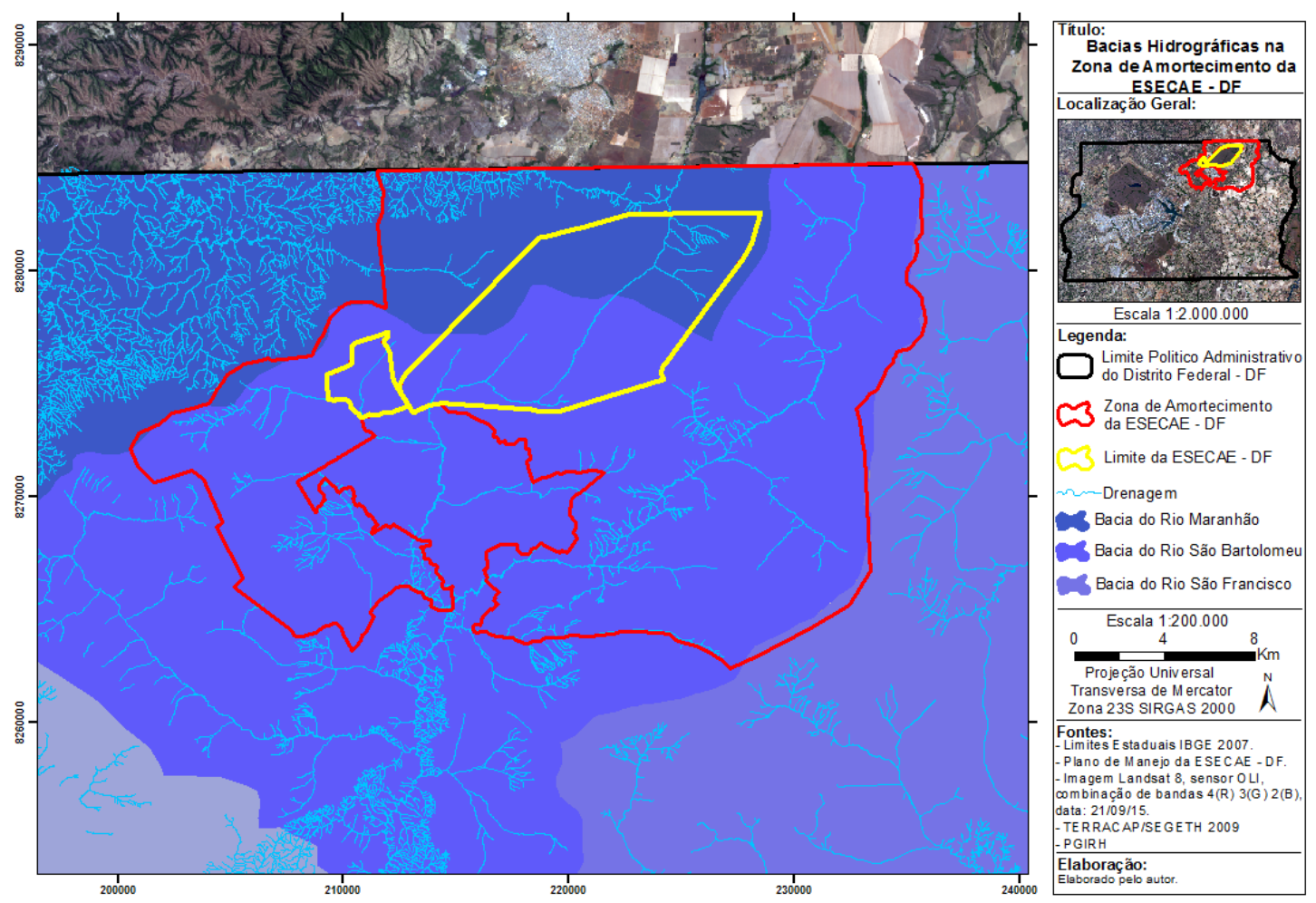

Figura 3: Bacias que banham a ZA da ESECAE. 
De acordo dom o Plano de Ordenamento Territorial - PDOT, predomina na área a Zona Rural de Uso controlado, Figura 4 e Figura 5.
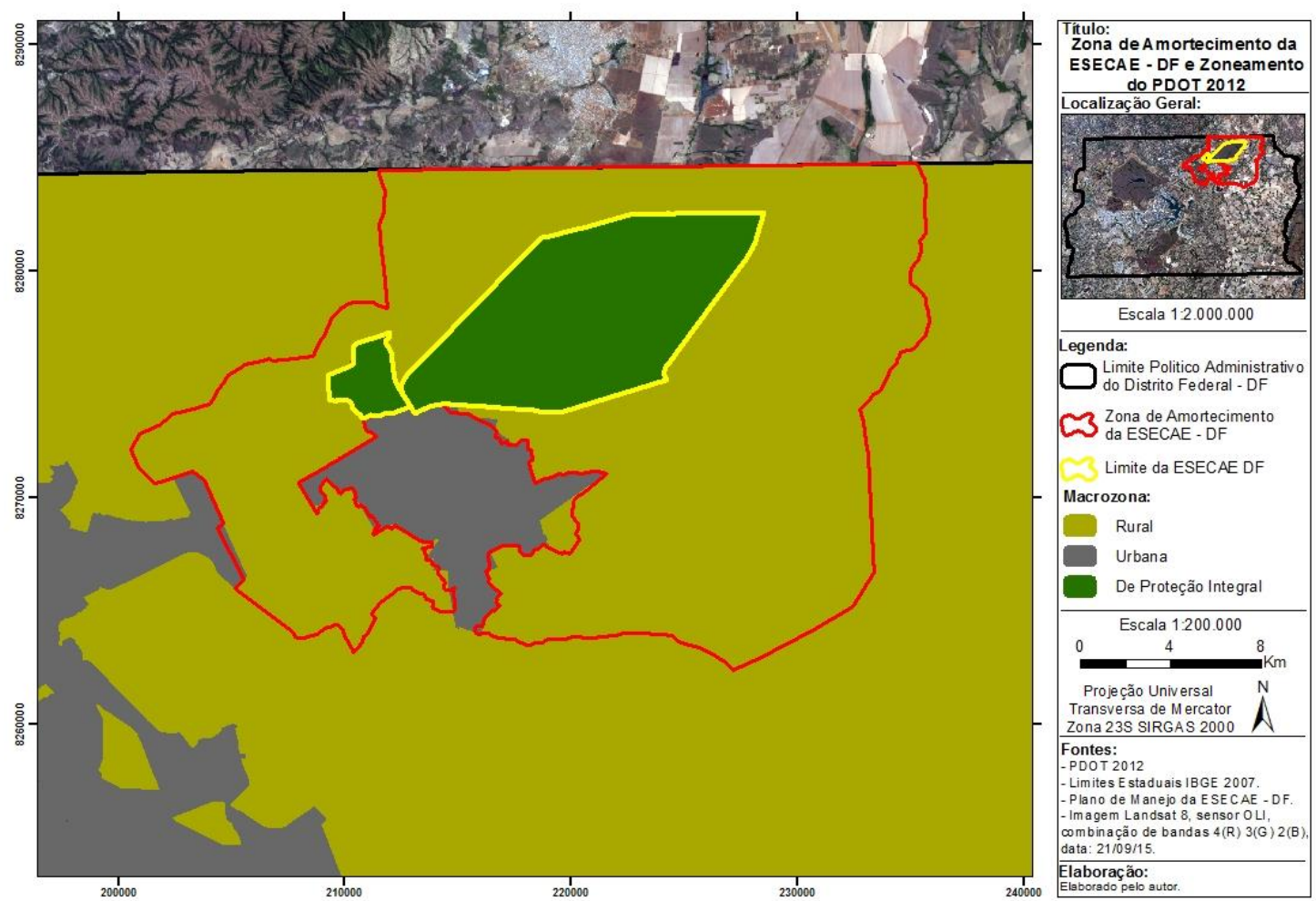

Figura 4: Zoneamento do PDOT.
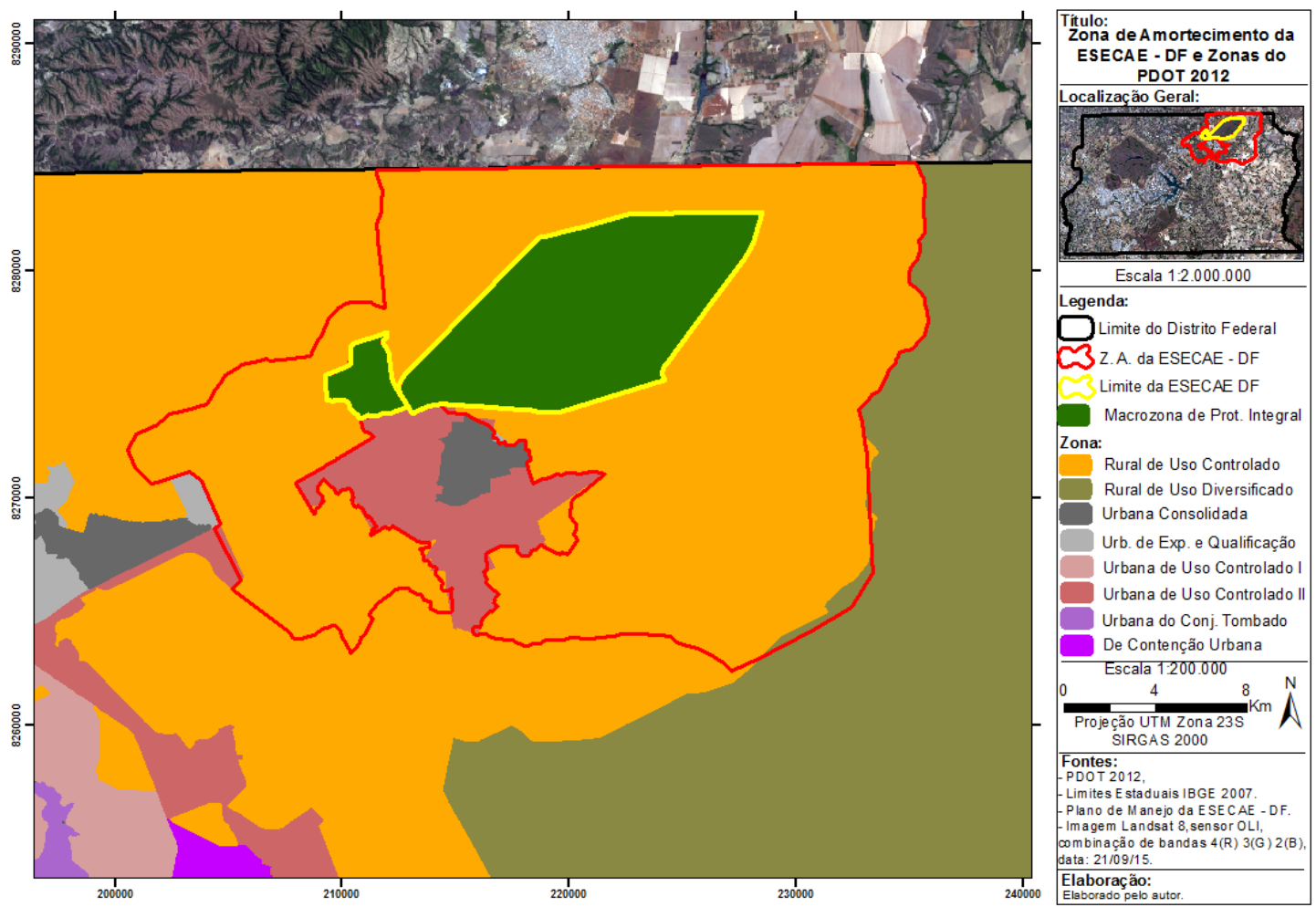

Figura 5: ZA da ESECAE DF e Zonas do PDOT. 
Cabe ainda mencionar que a Macrozona de Proteção Integral, da qual faz parte a área da ESECAE DF, é destinada à preservação da natureza, admitindo-se por determinação do PDOT apenas o uso indireto dos recursos naturais.
Os procedimentos metodológicos para a presente pesquisa se consistiu nas seguintes etapas: revisão bibliográfica, pré-processamento, identificação de construções e validação, conforme Figura 6.

\section{Material e métodos}

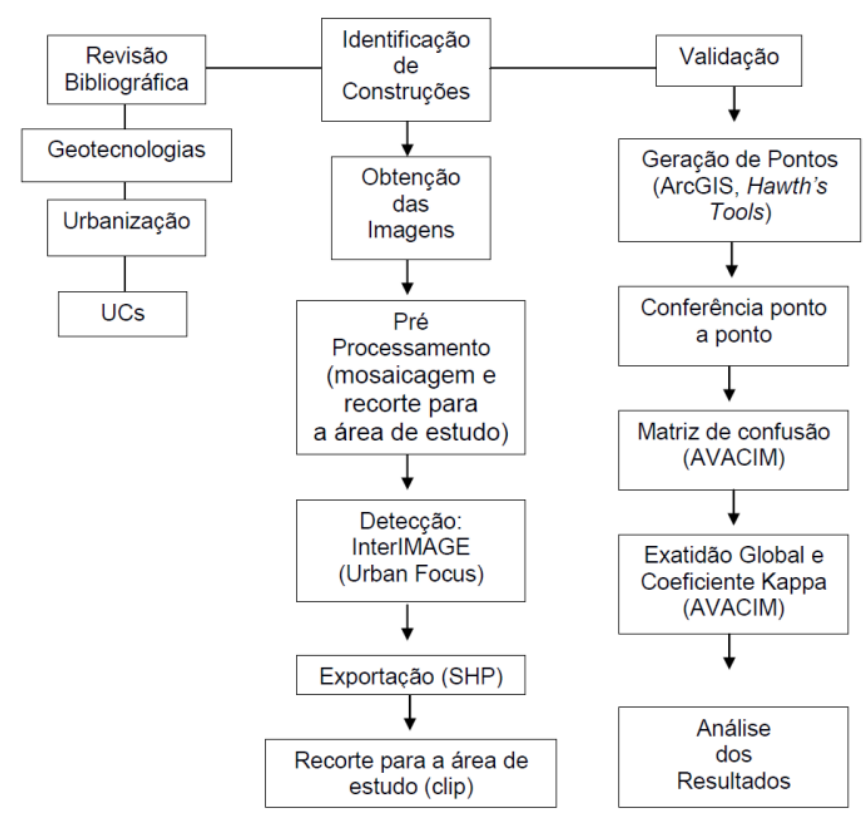

Figura 6: Procedimentos Metodológicos.

Para a detecção de construções foram utilizadas imagens da plataforma RapidEye, obtidas pelo Geocatálogo do MMA. Essa plataforma se destaca entre os novos sistemas de imageamento, visto que pode gerar imagens de um mesmo ponto do globo terrestre todos os dias.

Os dados do sistema RapidEye fornecem cinco bandas espectrais: azul, verde, vermelho, red edge, e infravermelho próximo (BRODIE et al, 2018). De acordo com Esetlili et al (2018, p. 233), o RapidEye é uma missão comercial de observação da Terra formada por uma constelação de cinco satélites e fornece imagens multiespectrais de alta resolução em cinco bandas ópticas na faixa de 400 a $850 \mathrm{~nm}$.

A resolução espacial dessas imagens é de 6,5 metros originalmente, a qual é incrementada para 5 metros após ortorretificação. Em decorrência desse processo as imagens corrigidas apresentam precisão compatível com a escala de 1:25.000,00.

Segundo Ban et al (2014, p. 2), a caracterização e o monitoramento da cobertura do solo a partir de imagens de alta resolução espacial permite a identificação de feições na escala da maioria das atividades humanas.

Esse trabalho se fundamentou no uso dos seguintes SIGs: ENVI, InterIMAGE, ArcGIS e Ferreira, M. R.F.; Steinke, V. A.; Bias, E.S.; Campos, N. L. O.
AVACIM (PRINA, 2014). A utilização de cada uma delas está detalhada a seguir.

Os procedimentos de pré - processamento foram realizados no software ENVI, versão 5.3, de sensoriamento remoto do ambiente, os quais consistiram de mosaicagem de 4 cenas da plataforma RapidEye, todas do ano 2014, e recorte para a área de estudo.

Os procedimentos de processamento para detecção de loteamentos e construções foram realizados no software InterIMAGE, versões $1.43 \mathrm{e}$ 1.42 , com uso do operador brec urban focus.

O urban focus detecta áreas construídas, supondo-se que edifícios e outras estruturas artificiais construídas exibam mais contraste do que muitos ambientes naturais (Iannelli et al, 2014). Além disso, o urban focus calcula e combina o contraste entre várias direções com um tamanho de janela na ordem de $100 \mathrm{~m} \times 100 \mathrm{~m}$ (Iannelli et al, 2014). Nessa escala, a direcionalidade devido à rede rodoviária é descartada, e somente o alto contraste devido às estruturas construídas é capturado (Iannelli et al, 2014).

As características espectrais são muito relevantes para caracterizar as diferentes partes do ambiente urbano, ou para discriminar materiais artificiais e naturais, ou finalmente para detectar elementos naturais dentro dos limites urbanos. 
Para isso, foi utilizada a banda 3, função da diferenciação entre área urbana e correspondente ao canal do vermelho, com comprimento de onda entre 630 e $685 \mu \mathrm{m}$, em vegetação, Figura 7.

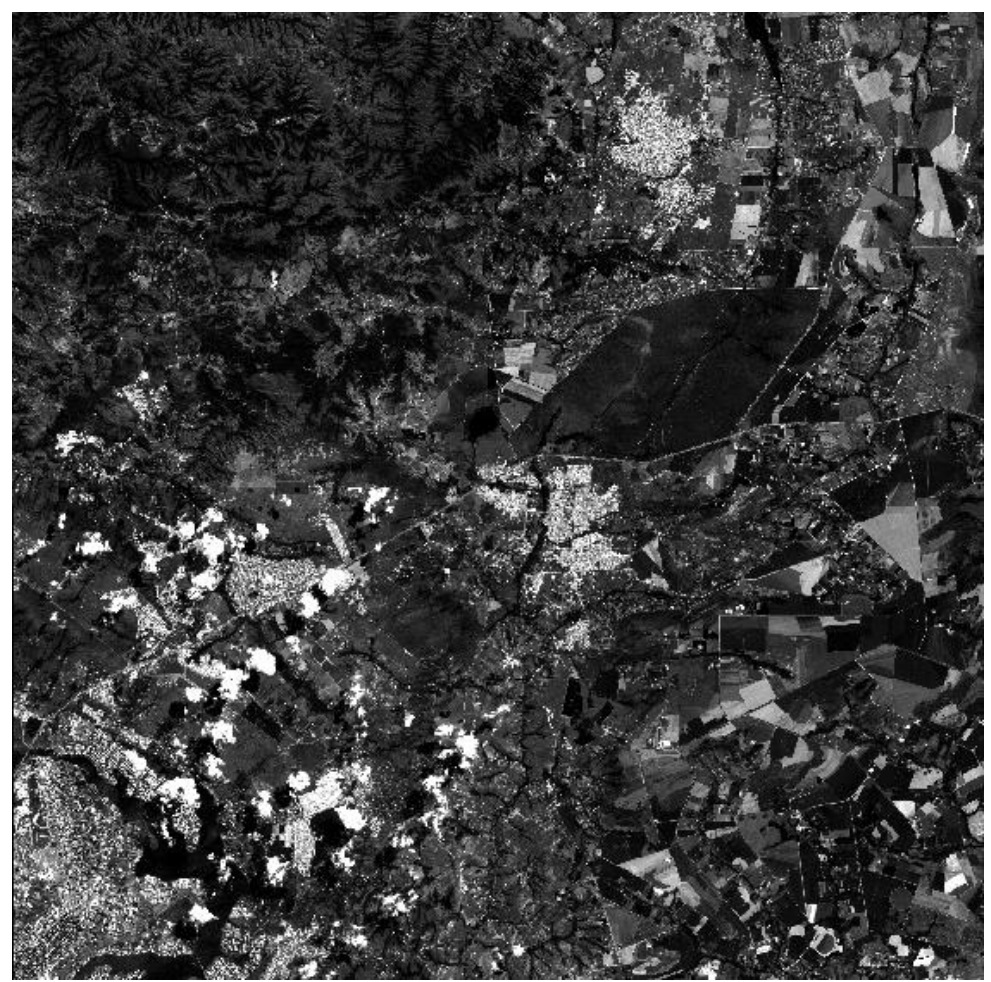

Figura 7: Mosaico de Imagens RapidEye 2014.

O processamento no InterIMAGE é baseado em regras de decisão, e para o detecção dos loteamentos foi utilizado o nó
UF, Figura 8. E os valores utilizados para os parâmetros estão indicados na Figura 9.

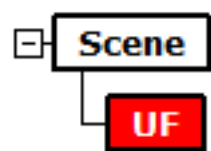

Figura 8: Regra de Decisão. 


\begin{tabular}{|ll}
\hline Name & Value \\
\hline Generic & \\
BottomUp Decision Rule &. \\
BottomUp Operator & Dummy BottomUp \\
Breakpoint & None \\
Class & UF \\
Color & \\
TopDown Decision Rule & \\
TopDown Multi-Class & \\
\hline TopDown Operator & \\
\hline BottomUp & BREC Urban Focus \\
TopDown & \\
a) Input Image & image \\
b) Low-Pass Filter Kernel (in meters) & 30 \\
c) Threshold & 130000 \\
d) Label Image Resolution & 5 \\
e) Reliability & 0.2 \\
\hline
\end{tabular}

Figura 9: Parâmetros Utilizados.

Em OBIA, valores apropriados de treshold são um grande passo para melhores resultados da classificação (HYDAYAT et al, 2018, p.10).
Essa sequência de procedimentos foi executada para o recorte do mosaico das quatro imagens do ano 2014, representado na Figura 10.

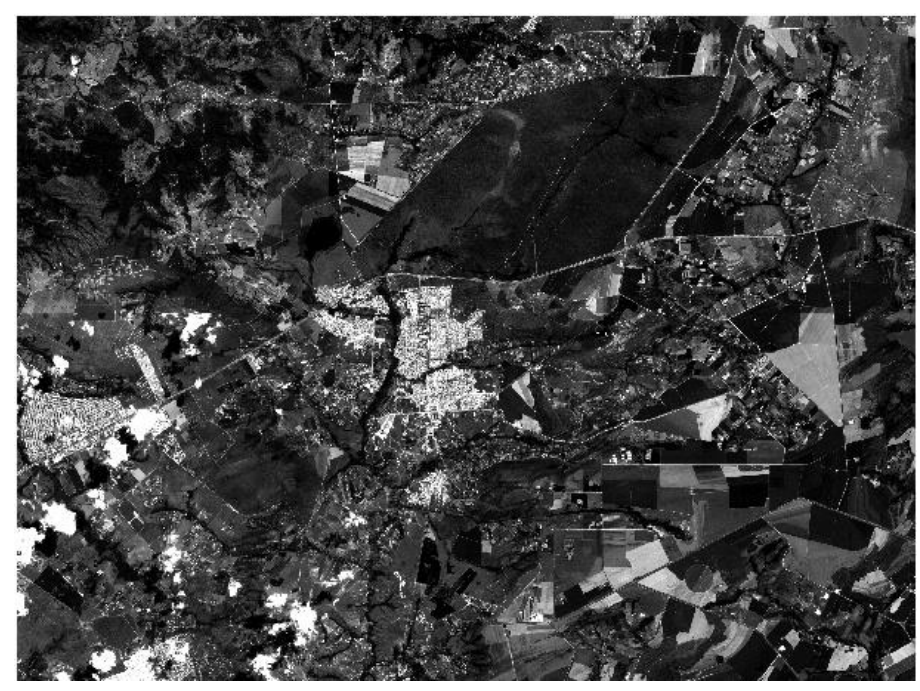

Figura 10: Recorte para a área de estudo.

Validação dos Dados

Após o processamento com uso do brec urban focus, o resultado foi exportado para o formato shapefile. Para a etapa de validação, primeiramente os polígonos foram unidos a partir da ferramenta merge, recortados com o polígono da
Zona de Amortecimento da ESECAE DF a partir da ferramenta clip, e então, a partir do polígono resultante, foram gerados 100 pontos para conferência visual mediante confrontação com aerofotos com resolução espacial de $24 \mathrm{~cm}$, originárias de aerolevantamento realizado pela Terracap no ano de 2014. 


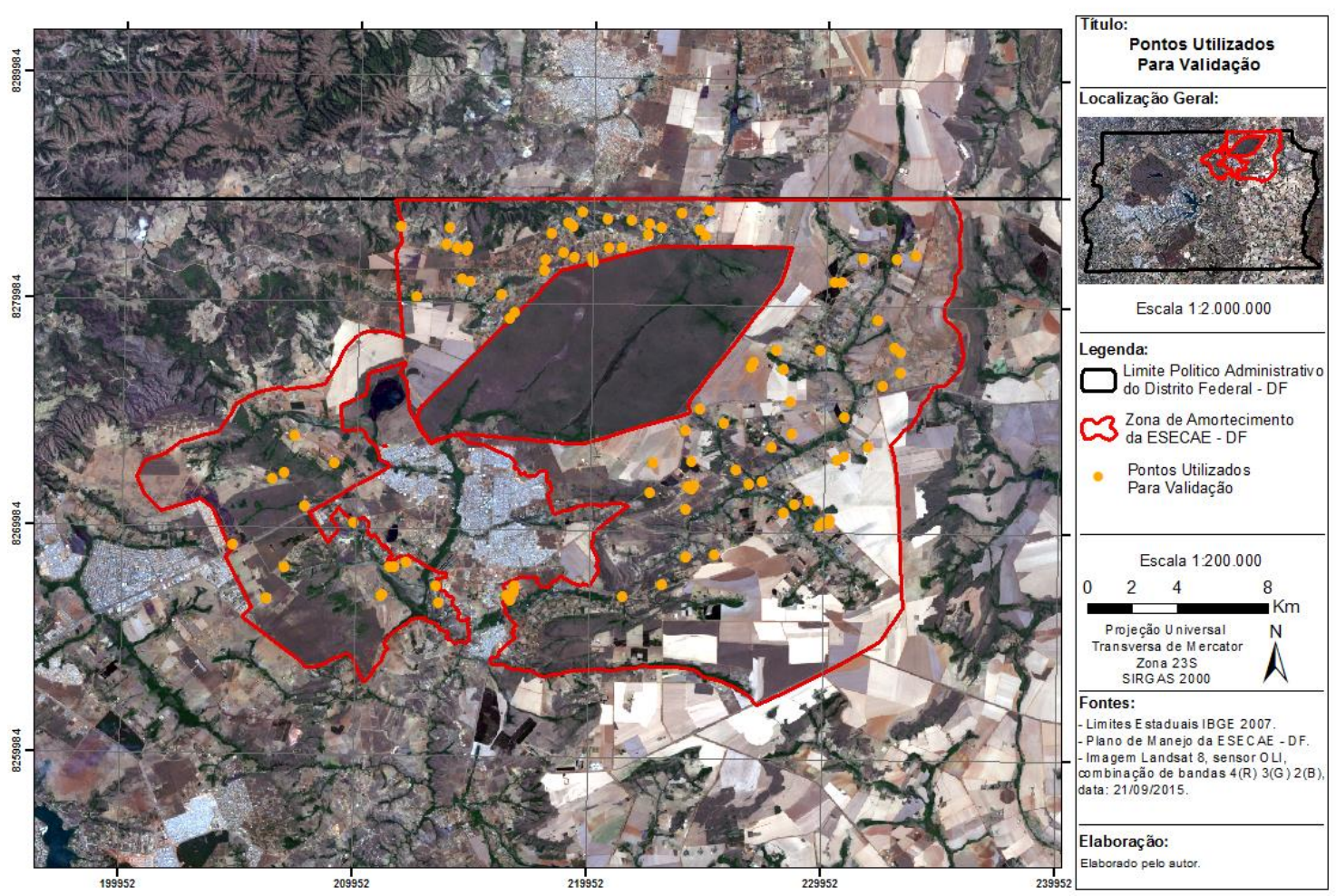

Figura 11: Pontos utilizados para validação.

Cabe acrescentar que os pontos foram gerados por meio da ferramenta hawth's tools para ArcGIS, e separados em duas categorias: loteamento/construções e não loteamento. A identificação dessas duas categorias se deu pela criação do campo loteamento/construções na tabela de atributos do arquivo referente aos pontos, e então cada ponto foi confrontado com as aerofotos e identificado pelas palavras sim (loteamento/construções) ou não (não loteamento).Com isso foi gerada a matriz de confusão da amostra, e consequentemente gerados os índices de qualidade, ambos com uso do aplicativo AVACIM - Avaliador de Classificação de Imagens (PRINA, 2014) conforme o seguinte fluxo de procedimentos:

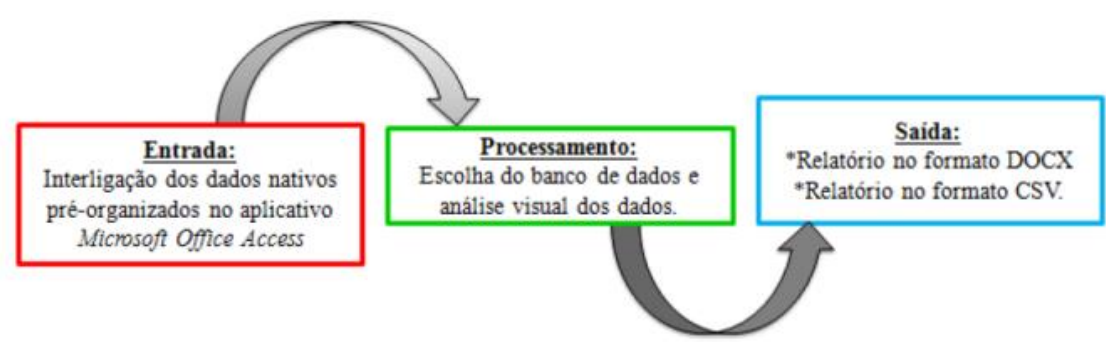

Figura 12: Fluxo de procedimentos no AVACIM. Fonte: Prina (2014). 
A tabela referente ao banco de dados

elaborado no Microsoft Office Access está representada na Figura 13.

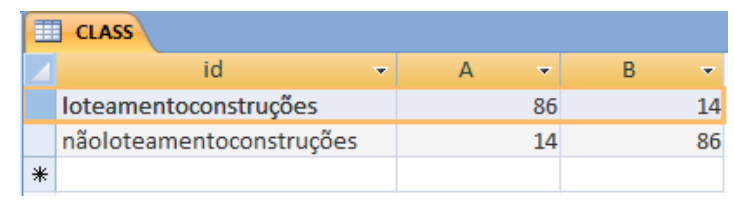

Figura 13: Banco de dados Access

Os índices de qualidade foram adquiridos pelos cálculos referentes aos erros de inclusão, erros de omissão, exatidão global da análise, Concordância entre a classificação e os dados de referência (Q) e Coeficiente Kappa, efetuados no AVACIM (Prina, 2014), os quais se deram conforme as fórmulas indicadas a seguir:

$$
\begin{gathered}
\text { Erro de Inclusão }=\frac{1-(\text { Diagonal Principal })}{\sum \text { total }(\text { referência })} \\
\text { Erro de Omissão }=\frac{1-(\text { Diagonal Principal })}{\sum \text { total }(\text { classificação })} \\
\text { Exatidão Global }=\frac{\sum \text { Diagonal Principal }}{\sum \text { de todos os dados }} \\
K \text { da coluna classificação }(i) * \sum \text { da linha de referência }(i) \\
\sum \text { de todos os dados } \\
K=\frac{D-Q}{T-Q}
\end{gathered}
$$

Figura 14: Fórmulas dos índices de qualidade. Fonte: Prina (2014).

Onde, de acordo com Prina (2014, p. 3), "K" é o coeficiente Kappa, "Q" é a concordância entre a classificação e os dados de referência, "D" é o total de correto que foi obtido com a classificação e "T" é o total de dados da amostra.

O coeficiente kappa é uma medida de concordância entre a interpretação e a verificação, que não só representa o número de unidades corretamente classificadas, mas também comissões e omissões (Kanga, 2017). Ele resume, em um único valor, todos os dados incluídos na matriz de confusão (Balboa et al, 2018). Esta medida de concordância assume valor máximo igual a 1 , que representa total concordância ou ainda pode assumir valores próximos e até abaixo de 0 , os quais indicam nenhuma concordância (Herculano, 2016). É uma das medidas mais populares para abordar a correspondência em uma classificação (Achicanoy et al, 2018).

Trabalhos temáticos podem ser classificados quanto à qualidade, com base no índice Kappa, de acordo com a Tabela 1. 
Tabela 1 - Qualidade Baseada no Índice Kappa.

\begin{tabular}{cl}
\hline Índice Kappa (k) & Nível de Concordância \\
\hline $\mathrm{k}<0$ & Péssimo \\
$0<\mathrm{k} \leq 0,2$ & Ruim \\
$0,21 \leq \mathrm{k} \leq 0,4$ & Razoável \\
$0,41 \leq \mathrm{k} \leq 0,6$ & Bom \\
$0,61 \leq \mathrm{k} \leq 0,8$ & Muito bom \\
$0,81 \leq \mathrm{k} \leq 1,0$ & Excelente
\end{tabular}

Fonte: Adaptado de Landis e Koch (1977).

A exatidão global é dada pela a razão entre o total de elementos classificados corretamente, células da diagonal principal,

\section{Resultados e discussão}

Após o processamento da

metodologia de detecção no e o número total de elementos na matriz (Ariza-Lopez et al, 2018).

InterIMAGE,foram identificadas inúmeras manchas de loteamentos com construções estabelecidas, bem como áreas urbanas consolidadas, as quais podem ser visualizados na Figura 15.

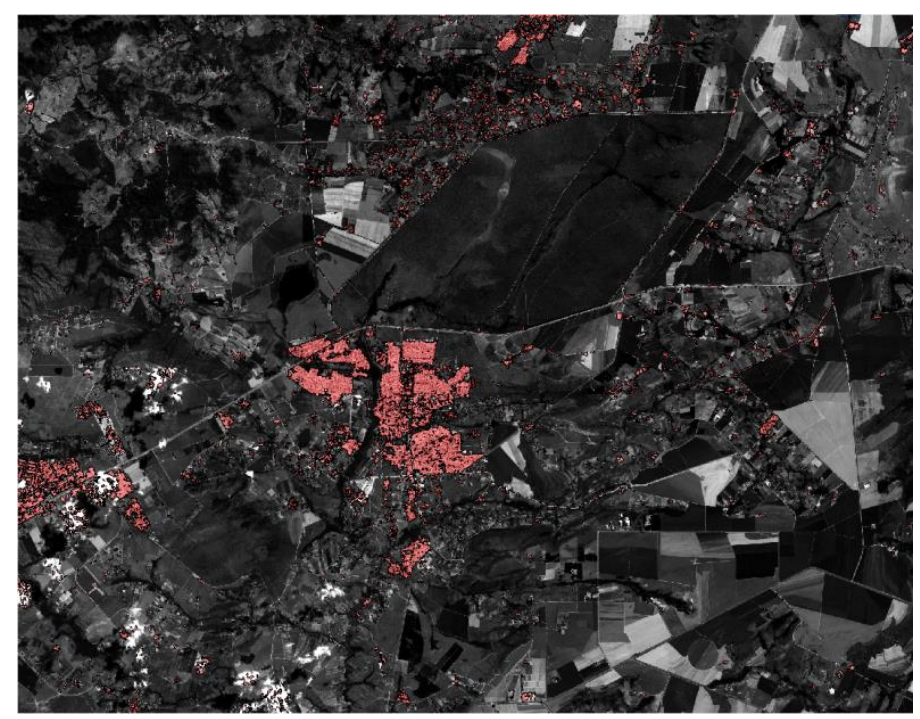

Figura 15: Resultado.

Os resultados obtidos indicaram loteamentos e construções dentro da Zona de
Amortecimento da ESECAE-DF, representados na Figura 16. 


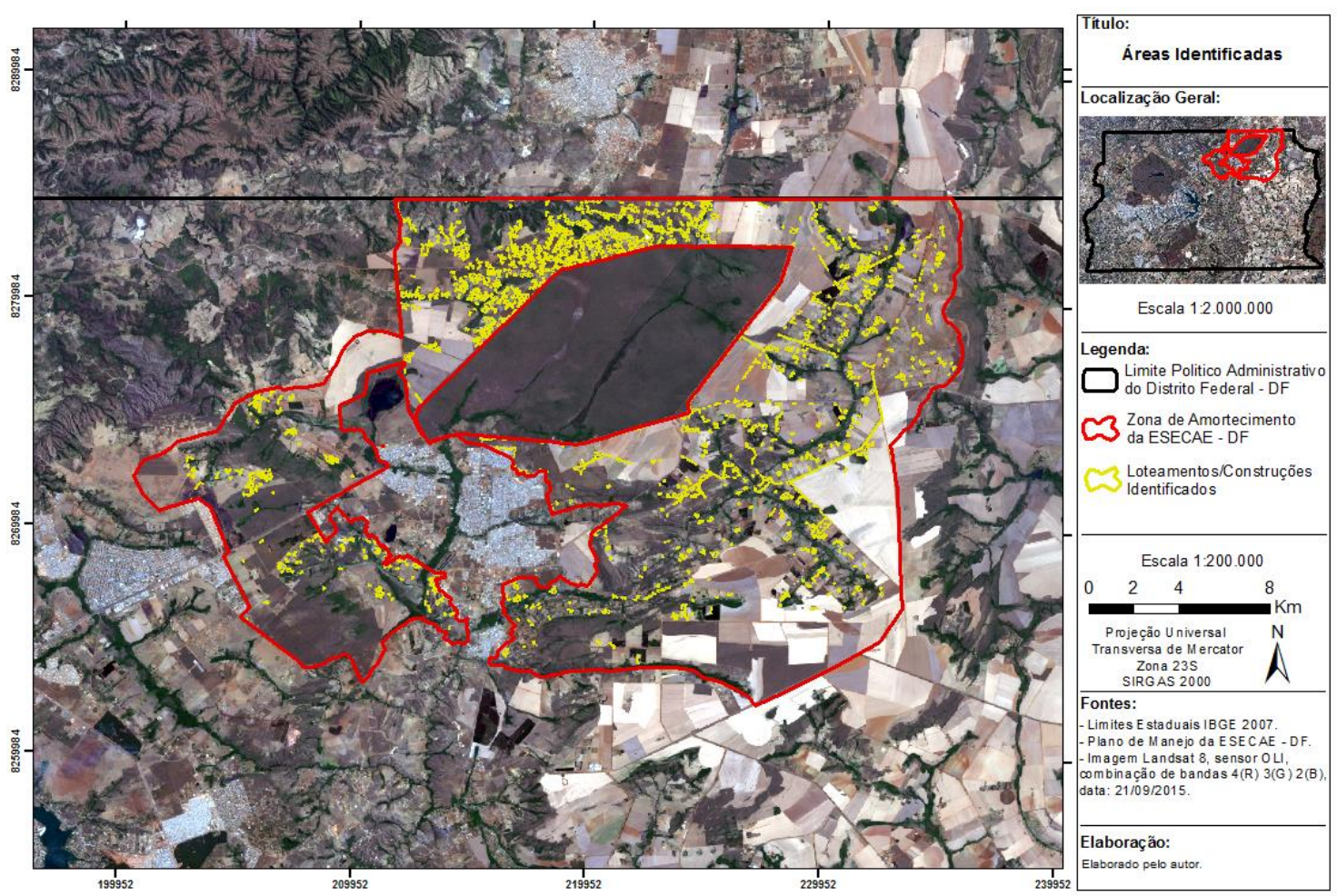

Figura 16: Áreas identificadas (ano 2014).

A Figura 17 destaca um exemplo de loteamento identificado no mosaico referente ao ano de 2014. Cabe esclarecer que na composição da figura em questão foram utilizadas aerofotos do ano de 2014 pra visualização.

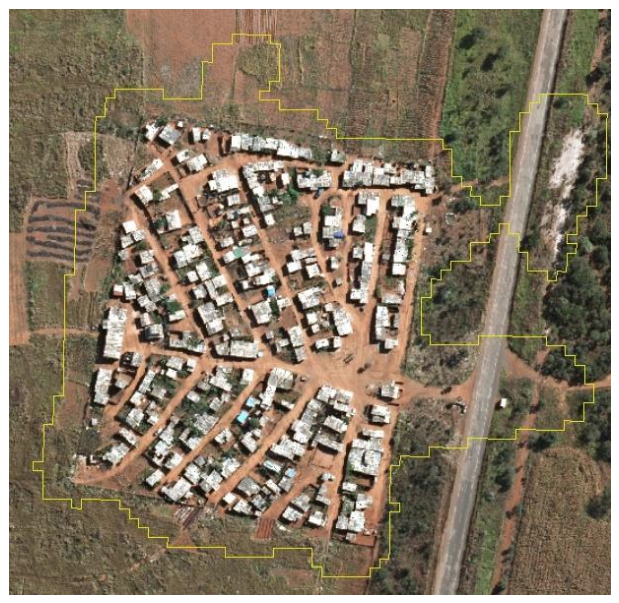

Figura 17: Exemplo de Loteamento Identificado.

Dos 100 pontos gerados para validação do resultado obtido para o ano de 2014, por conferência visual com o mosaico de aerofotos da Terracap (ano 2014), 86 pontos apontaram locais que indicavam loteamentos/construções e os outros 14 pontos indicaram áreas que não eram loteamentos, eram principalmente áreas de solo exposto.

Para isso, foram considerados como loteamentos/construções aqueles pontos que estavam dentro de polígonos que englobaram áreas com construções. E aqueles pontos que indicaram polígonos em que não haviam 
construções,marcadamente áreas de solo exposto, foram considerados como não loteamento. As Figuras 18 e 19 mostram respectivamente exemplos de pontos considerados loteamento/construções e não loteamento.

como

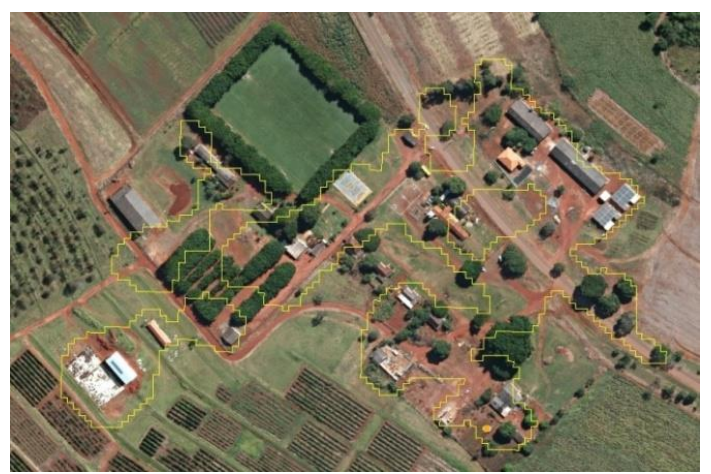

Figura 18: Exemplo de ponto considerado como loteamento/construções

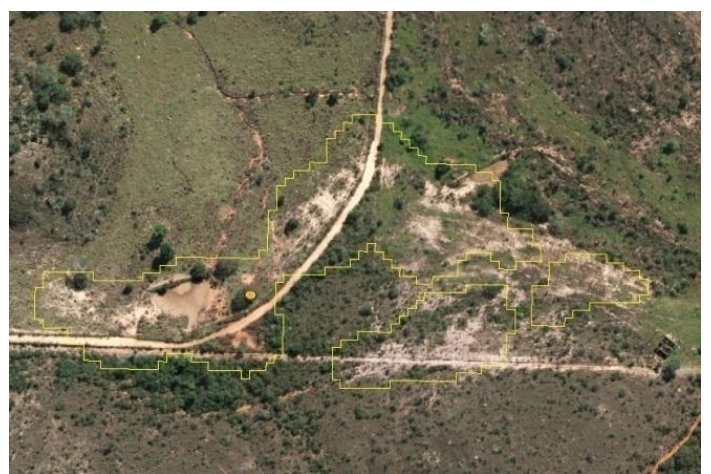

Figura 19: Exemplo de ponto considerado como não loteamento

A partir desses pontos, a matriz de confusão gerada e o processamento pelo aplicativo AVACIM - Avaliador de Classificação de Imagens
(Prina, 2014) indicaram o índice Exatidão Global de 0,86 , e o índice Kappa de 0,72, conforme apresentado na Figura 20.

\begin{tabular}{|c|c|c|c|}
\hline A & $B$ & Soma & Inclusão \\
\hline 86 & 14 & 100 & 0,1400 \\
\hline 14 & 86 & 100 & 0,1400 \\
\hline 100 & 100 & $\varepsilon==$ Som & \\
\hline 0,1400 & 0,1400 & $<==$ Omissão & \\
\hline & & & \\
\hline$Q \Rightarrow$ & 100,000000 & & \\
\hline Kappa=> & 0,720000 & & \\
\hline & & & \\
\hline
\end{tabular}

Figura 20: Matriz de Confusão com índices calculados.

Além dos resultados gerados na matriz de confusão, o AVACIM - Avaliador de Classificação de Imagens (Prina, 2014) também gera um relatório informativo, o qual está indicado na Figura 21. 


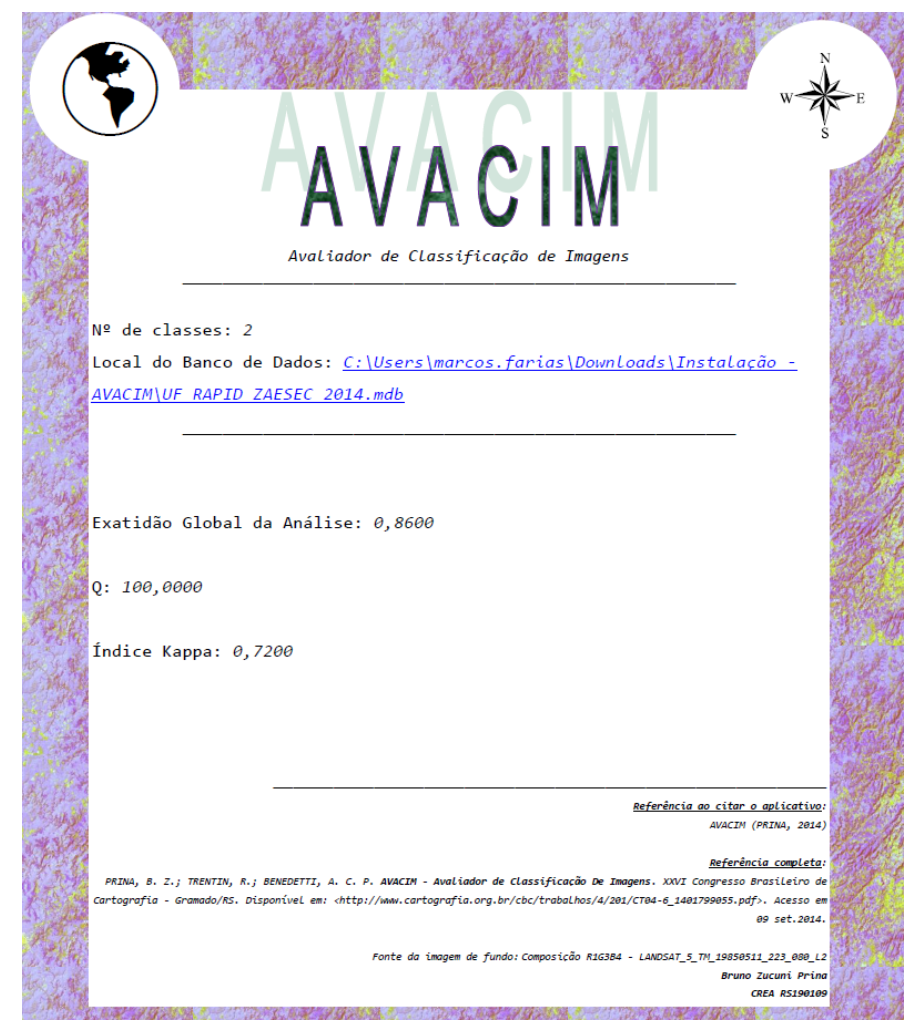

Figura 21: Relatório gerado pelo AVACIM.

O índice Kappa obtido de 0,72 permite enquadrar o dado gerado, quanto ao nível de concordância, como muito bom conforme parâmetros apresentados anteriormente na Tabela 1. Tal resultado permite afirmar que o operador brec urban focus é uma ferramenta útil para detecção de áreas em processo de urbanização, inclusive para a identificação de loteamentos consolidados e em processo de consolidação.

Uma vez que, as manchas de loteamentos/construções detectadas podem ser facilmente convertidas para o formato shapefile e confrontadas com imagens de alta ou altíssima resolução espacial, como foi o caso das aerofotos utilizadas neste trabalho.

Essa confrontação do resultado decorrente do uso do operador brec urban focus com aerofotos permite a identificação dos polígonos que são realmente áreas em processo de urbanização, com loteamentos e construções, e a diferenciação de polígonos que representam áreas de solo exposto. Proporcionando assim a identificação dos polígonos representativos de áreas com loteamentos e construções.

Dessa forma, ações de fiscalização podem ser beneficiadas pela utilização dessa ferramenta, bem como pela metodologia de validação adotada neste trabalho, com vistas ao controle de ocupações irregulares na área abrangida pela zona de amortecimento da ESECAE DF, constituindo-se então como ferramentas de apoio para a gestão do território.

Considerações sobre o limite da Zona de Amotecimento da ESECAE DF

A delimitação da Zona de Amortecimento da ESECAE - DF pelo limite político administrativo do Distrito Federal em sua porção norte, desconsidera a importância da zona de amortecimento par a mitigação dos efeitos na unidade de conservação da natureza, decorrentes da ação antrópica existente no entorno, já que foi priorizado um critério político administrativo.

$O$ fato de que a ESECAE -DF divide duas regiões hidrográficas de alcance nacional, as bacias do Rio Paraná e dos Rios Tocantins/Araguaia foi desconsiderada no seu processo de delimitação.

A exclusão da Macrozona Urbana da poligonal da Zona de Amortecimento expõe a ESECAE - DF a fragilidades em sua porção sul, visto que a área não está sujeita às recomendações feitas no Plano de Manejo. Esse trecho excluído é limítrofe com a área da unidade de conservação da natureza, deixando-a desprotegida em função da ausência de Zona de Amortecimento nesse trecho. 
De acordo com a Lei 9985/2000, no parágrafo único do artigo 49 , recepcionado pela Lei Complementar Distrital 827/2010, a zona de amortecimento das unidades de conservação de proteção integral, uma vez formalmente criada, não pode ser transformada em zona urbana. Porém, não há vedação legal para a inclusão de uma zona urbana preexistente à área de uma zona de amortecimento. Dessa forma, não haveria impedimento legal para a inclusão da Macrozona urbana no limite da Zona de Amortecimento da ESECAE DF, visto que preexistente à sua criação formal.

A inclusão da Macrozona Urbana contemplaria a porção sul do trecho da ESECAE DF onde está localizada a Lagoa Bonita, e poderia incluir recomendações específicas para essa área que é considerada de risco para ocupações irregulares e grilagem como foi anteriormente indicado na Figura 3, atuando assim como mais um instrumento de gestão territorial. Ressalta-se que o trecho da ESECAE DF em que está localizada a Lagoa Bonita não está contemplado pela zona de amortecimento em sua porção sul.

Evidencia-se que a poligonal foi elaborada segundo um processo que privilegiou critérios políticos administrativos em detrimento de critérios de preservação da ESECAE DF, unidade de conservação da natureza que transcende em relevância ambiental os limites do Distrito Federal e o Zoneamento do PDOT DF.

Recomenda-se a revisão da poligonal da Zona de Amortecimento da ESECAE DF com vistas ao estabelecimento de uma nova poligonal que considere as bacias hidrográficas que abrangem a ESECAE DF, bem como que considere a proteção de toda a área da Estação Ecológica para mitigação dos efeitos da ação antrópica existente no entorno. Bem como, que seja considerado o entorno da ESECAE DF que se encontra em outras unidades federativas, marcadamente no estado do Goiás, tendo em vista a relevância desta unidade de conservação da natureza para as regiões hidrográficas do Rio Paraná e dos Rios Tocantins e Araguaia, as quais transcendem os limites do Distrito Federal e têm relevância nacional. Para isso, seria necessária a integração entre os governos do Distrito Federal e do Goiás para uma revisão conjunta da poligonal da Zona de Amortecimento da ESECAE DF.
A Zona de Amortecimento da ESECAE DF não poderá ser convertida em Zona Urbana em atendimento a lei federal 9985/2000 e a lei distrital $827 / 2000$. Porém, neste trabalho foram identificados loteamentos com construções consolidadas dentro dos limites da Zona de Amortecimento da ESECAE - DF.

O operador brec urban focus, presente nas versões 1.42 e 1.43 do software InterIMAGE, é eficiente para a detecção de áreas urbanas e de construções em imagens do sistema RapidEye. Porém, há que ser mencionado que áreas de solo exposto também foram identificadas pelo operador. Além disso, para a utilização do operador em conjuntos de imagens do sistema RapidEye obtidas em outros anos é necessário o ajuste dos valores dos parâmetros low-Pass filter kernel, threshold, label image resolution e realiablity.

O tempo de processamento pelo InterIMAGE foi demasiadamente longo, por diversas vezes foi necessário mais de 18 horas de processamento para obtenção de resultados. Além disso, ocorreram travamentos constantes do software.

A validação do resultado obtido para o ano de 2014, a partir de conferência com aerofotos do mesmo ano, se mostrou eficiente e de baixo custo, visto que não foi necessária a ida a campo e que as ferramentas utilizadas são gratuitas.

A ferramenta hawth's tools para ArcGIS se mostrou eficiente e de fácil utilização para a geração dos pontos para a conferência com as aerofotos.

O AVACIM - Avaliador de Classificação de Imagens (Prina, 2014) proporcionou o cálculo rápido da Exatidão Global e do índice Kappa, permitindo assim a avaliação da qualidade do resultado obtido para o ano de 2014. O aplicativo atendeu satisfatoriamente às necessidades dessa pesquisa, visto a grande agilidade e operacionalidade ao realizar a validação dos resultados.

Ressalta-se que o índice Kappa obtido de 0,72 enquadrado como muito bom na Tabela 1 , permite validar a utilização do operador brec urban focus para detecção de loteamentos com áreas construídas em imagens RapidEye.

\section{Conclusões}




\section{Agradecimentos}

Os autores agradecem ao Instituto Brasília Ambiental e ao PPGEA UnB pelo apoio durante a execução desse trabalho.

\section{Referências}

Achicanoy, J.A.; Rojas-Robles, R., Sanchez, J.E. 2018. Análisis y proyección de las coberturas vegetales mediante el uso de sensores remotos y Sistemas de Información Geográfica en la localidad de Suba, Bogotá-Colombia. Géstion e Ambiente, Volumen 21, Número 1, pp. 41-58. Disponível em: < https://revistas.unal.edu.co/index.php/gestion/a rticle/view/68285>. Acesso em: 14 ago. 2018.

Andrade, F.M.; Lourenço, R.W. 2016. Uso do Solo e Cobertura Vegetal na Bacia Hidrográfica do Rio Una - Ibiúna SP. RGD Revista do Departamento de Geografia USP, V. 32, pp 4860. Disponível em: < https://www.revistas.usp.br/rdg/article/view/11 6342>. Acesso em: 25 jul. 2018.

Ariza-Lopez, J.F.; Rodriguez-Avi, J., AlbaFernandez, V. 2018. Control Estricto de Matrices de Confusión por Medio de Distribuciones Multinominales. GeoFocus, $\mathrm{n}^{\circ}$ 21, pp. 215-226. Disponível em: < http://www.geofocus.org/index.php/geofocus/a rticle/view/591/460>. Acesso em: 14 ago. 2018.

Balboa, J.L.G.; Fernandez, M.V.A.; Lopez, F.J.A.; Avi, J.R. 2018. Analysis of Thematic Similarity Using Confusion Matrices. Internacional Journal of Geo-information, 7(6), 233, Disponível em: < http://www.mdpi.com/22209964/7/6/233/htm>. Acesso em: 25 jul. 2018.

Ban, Y.; Jacob, A.; Gamba, P. 2015. Spaceborne SAR data for global urban mapping at $30 \mathrm{~m}$ resolution using a robust urban extractor. ISPRS Journal of Photogammetry and Remote Sensing 103, 28-37. Disponível em: < https://www.researchgate.net/publication/2670 47724_Spaceborne_SAR_data_for_global_urb an_mapping_at_30_m_resolution_using_a_rob ust_urban_extractor>. Acesso em: 14 ago. 2018.

Blaschke, T.; Hay, J.G.; Kelly, M.; Lang, S.; Hofmann, P.; Addink, E.; Feitosa, R.Q.; Meer, F.V.D.; Werff, H.V.D.; Collie, V.F.; Tiede, D. 2014. Geographic Object-Based Image Analysis - Towards a New Paradigm. ISPRS Journal of Photogammetry and Remote Sensing, vol. 87, january 180-191. Disponível em:

https://www.sciencedirect.com/science/article/
pii/S0924271613002220>. Acesso em: 19 jul. 2018.

Brodie, J.; Ash, V.L.; Titley, I.; Yesson, C. A 2018. Comparison of Multispectral Aerial and Satellite Imagery for Mapping Intertidal Seaweed Communities. Aquatic Conservation Marine and Freshwater Ecosystems, 1-10. Disponível em: < https://www.researchgate.net/profile/Lauren_A sh2/publication/325017648_A_comparison_of _multispectral_aerial_and_satellite_imagery_f or_mapping_intertidal_seaweed_communities/l inks/5af5fba0aca2720af9c6ce2d/A-

comparison-of-multispectral-aerial-andsatellite-imagery-for-mapping-intertidalseaweed-communities.pdf>. Acesso em: 13 ago. 2018.

Chen, G.; Weng, Q; Hay, J. G.; He, Y. 2018. Geographic object-based image analysis (GEOBIA): emerging trends and future opportunities, GIScience \& Remote Sensing, 124. Disponível em: < https://www.researchgate.net/publication/3223 67962_Geographic_Object-

Based_Image_Analysis_GEOBIA_Emerging_t rends_and_future_opportunities>. Acesso em: 24 jul. 2018.

Chen, G.; Weng, Q. 2018. Special issue: Remote sensing of our changing landscapes with Geographic Object-based Image Analysis (GEOBIA), GIScience \& Remote Sensing, , 55:2, 155-158. Disponível em: < https://www.tandfonline.com/doi/full/10.1080/ 15481603.2018.1436953>. Acesso em: 24 jul. 2018.

Cury, Katia. 2013. Roteiro metodológico para elaboração de planos de manejo para as unidades de conservação do Distrito Federal. Brasília: IBRAM.

Dolui, S. 2018. Methods of water body extraction based on Remote Sensing \& GIS techniquies (A case study of Bardhaman city and its surrounding fringe areas). International journal of basic and applied research, Volume 8, Número 7, , pp. 985-1003. Disponível em: < http://www.pragatipublication.com/assets/uplo ads/doc/6a690-0985-1003.13523.pdf>. Acesso em: 15 ago. 2018.

Esetlili, M.T.; Balcic, F.B.; Sanh, F.B.; Ustuner, M.; Kalkan, K.; Goksel, C.; Gazioglu, C.; Kurucu, Y. 2018. Comparison of Object and Pixel-Based Classifications for Mapping Crops Using Rapideye Imagery: A Case Study of Menemen Plain, Turkey. IJEGEO International Jornal of Environment and Geomatics, Vol: 5, Issue: 2, 231-243. Disponível em: < 
http://dergipark.gov.tr/download/articlefile/504770>. Acesso em: 13 ago. 2018.

Gomez, C.; White, J.C.; Wulder, M.A. 2016. Optical Remotely Sensed Data for Land Cover Classification: A Review. ISPRS Journal of Photogrammetry and Rmote Sensing, vol. 116, june 55-72. Disponível em: < https://www.sciencedirect.com/science/article/ pii/S0924271616000769>. Acesso em: 19 jul. 2018.

Herculano, R.N. 2016. Aplicação dos Métodos de Classificação de Imagem NDVI e ACP para o Mapeamento de Floresta Nativa da APA do Benfica no Município de Itaúna/MG: Uma Análise Comparativa. Cadernos do Leste, , 16, $\mathrm{n}^{\circ}$ 16, 98-113. Disponível em: < http://www.igc.ufmg.br/portaldeperiodicos/ind ex.php/leste/article/view/1125>. Acesso em: 25 jul. 2018.

Hidayat, F.; Rudiastuti, A.W.; Purwono, N.2018. GEOBIA an (Geographic) Object-Based Image Analysis for coastal mapping in Indonesia: A Review. IOP Publishing, 162, pp 1-18. Disponível em: http://iopscience.iop.org/article/10.1088/17551315/162/1/012039/pdf>. Acesso em: 25 jul. 2018.

Iannelli, G.C.; Lisini, G.; Dell'aqua, F.; Feitosa, R.Q.; Costa, G.A.O.P; Gamba, P. 2014. Urban Area Extent Extraction in Spaceborne HR and VHR Data Using Multi-Resolution Features. Sensors 14 (10), pp 18337-18352. Disponível em: < https:// http://www.mdpi.com/14248220/14/10/18337/htm>. Acesso em: 19 jul. 2018.

Kanga, S. 2017. Geospatial technique for Land use/Land cover mapping using satellite data: A case study of Bilaspur District (Himachal Pradesh), India. In: Construction Management, Mechanization and Environmental Sustainability, First edition, , White Falcon Publishing, pp 251-258. Disponível em: < https://www.researchgate.net/profile/Suraj_Sin gh52/publication/325869758_Soil_Erosion_As sessment_Using_Geospatial_Technique_A_Ca se_Study_of_North_Bihar_India/links/5b29f96 6a6fdcc72db4c3552/Soil-Erosion-AssessmentUsing-Geospatial-Technique-A-Case-Study-ofNorth-Bihar-India.pdf\#page $=265>$. Acesso em: 25 jul. 2018.

Katuta, A. M. 2013. A(s) Natureza(s) da Cartografia. In: Geograficidade, V.3, Número Especial, Primavera Disponível em: <http://www.uff.br/posarq/geograficidade/revis ta/index.php/geograficidade/article/view/139>. Acesso em: 08 jul. 2016.
Kerski, J.J. 2015. Geo-awareness, Geoenablement, Geotechnologies, Citizen Science, and Storytelling: Geography on the World Stage. Geography Compass, 9/1 pp 14-26. Disponível em: <http://spatial.usc.edu/wpcontent/uploads/2015/02/Kerski-Geoawareness-GeotechnologiesCitizenScience.pdf>. Acesso em: 16 nov. 2016. Landis, J. R; Koch, G. G. 1977. The measurement of observer agreement for categorical data. Biometrics 33, 159-174.

Leite, J.P.R.; Araujo, D.L.S; Duarte, M.D.D.C. 2018. Reflexos e Considerações sobre a Implementação do Cadastro Nacional de Unidades de Conservação do Estado do Piauí. Sustentare 2, 20-31. Disponível em: < http://periodicos.unincor.br/index.php/sustentar e/article/view/4413>. Acesso em: 13 ago. 2018.

Li, J.; Huang, X.; Gamba, P.; Dias, J.M.B.; Zhang, L.; Benediktsson, J.A.; Plaza, A. 2015. Multiple Feature Learning for Hyperspectral Image Classification. IEEE Transactions on Geoscience and Remote Sensing, vol. 53, no. 3, 1592-1606. Disponível em: < http://202.114.114.18/prof_web/zhangliangpei/ rs/publication/Multiple\%20Feature\%20Learnin g\%20for\%20Hyperspectral\%20Image\%20Clas sification.pdf.

Ma, L.; Manchun, L.; Ma, X.; Cheng, L.; Du, P.; Liu, Y. 2017. A review of Supervised ObjectBased Land-Cover Image Classification. ISPRS Journal of Photogammetry and Remote Sensing, vol. 130, 277-293. Disponível em: < https://www.sciencedirect.com/science/article/ pii/S092427161630661X>. Acesso em: 19 jul. 2018.

Ming, D.; Li, J.; Wang, J.; Zhang. M. 2015. Scale Parameter Selection by Spacial Statistics for Geobia: Using mean-shift based multi scale segmentation as an example. ISPRS Journal of Photogammetry and Remote Sensing, $106 \mathrm{pp}$ 28-41. Disponível em: < http://faculty.wwu.edu/wallin/envr442/pdf_file s/Ming_etal_2015_Scale\%20parameter\%20sel ection $\% 20$ by $\% 20$ spatial $\% 20$ statistics $\% 20$ for $\%$ 20GeOBIA\%20using\%20mean-

shift $\% 20$ based $\% 20$ multi-

scale\%20segmentation\%20as\%20an\%20xam ple_J_Photogram_and_Rem_sens.pdf $>$. Acesso em: 19 jul. 2018.

Nagne, A.D.; Dhumal, K.R.; Vibhute, D.A.; Kale, V.K.; Mehrotra, S.C.; Nalawade, B.D. 2018. Automatic Extraction of Built-Up area From EO-1 Hyperion Hyperspectral Satellite Image Based on NDBI Index. IJREAM International Journal for Research in Engineering Application \& Management, Special Issue, , 77- 
80.

Disponível

em:

$<$

https://www.ijream.org/papers/NCCT2018042. pdf $>$. Acesso em: 19 jul. 2018.

Oliveira, S.B.L.; Pinho, S.P.G.; Sá, S.A.; Gomes, A.A.; Junior, R.T.O.; Ferreira, R.P.; Turquia, P.H.S. 2017. Proposta de Subsídio para elaboração de um Plano de Manejo para os Córregos leão Deitado e Jacarandá, Afluentes do Ribeirão Tribuna, Zona Rural do Município de Ipatinga, MG. Revista NBC, 14, novembro de 2017, pp 127-139. Disponível em: < http://www3.izabelahendrix.edu.br/ojs/index.p hp/bio/article/view/1727/940>. Acesso em: 13 ago. 2018.

O'neill-Dunne, J.; Macfaden, S.; Royar, A. 2014. A Versatile, Production-Oriented Approach to High-Resolution Tree-Canopy Mapping in Urban and Suburban Landscapes Using GEOBIA and Data Fusion. Remote Sensing, , 6, pp 12837-12865. Disponível em: < http://www.mdpi.com/2072-

4292/6/12/12837/htm>. Acesso em: 23 jul. 2018.

Pires, P.S.; Rugine, V.M.T. 2018. Reconhecimento do Uso Público nos Parques Estaduais no Brasil com Enfase na Visitação Turística. Revista Brasileira de Ecoturismo 11, n. 1, fev/abr 2018, pp 61-80. Disponível em: < http://www.sbecotur.org.br/rbecotur/seer/index .php/ecoturismo/article/view/1134>. Acesso em: 13 ago. 2018.

Prina, B. Z.; Trentin, R.; Benedetti, A. C. P. 2014. AVACIM - Avaliador de Classificação de Imagens. Santa Maria, Universidade de Santa Maria, Departamento de Geociências.

Sibarudin, H.I.; Shafri, H.Z.M.; Pradhan, B.; Haron, N.A. 2018. Comparison of pixel-based and object-based image classification techniques in extracting information from UAV imagery data. IOPSCIENCE, vol. 169, pp 1-9. Disponível em: < http://iopscience.iop.org/article/10.1088/17551315/169/1/012098/meta>. Acesso em: 15 ago. 2018.

Rafiu, A.J.; Yusuf, O.A.; Christhopher, O.A.; Amoo, N.B. 2018. Spatio-Temporal Urban Expansion Analysis in a Growing City of Oyo Town ,Oyo State, Nigeria Using Remote Sensing And Geographic Information System (GIS) Tools. IJEGEO International Journal of Environment and Geoinformatics, 5(2), 2018, pp 104-113. Disponível em: < http://dergipark.gov.tr/ijegeo/issue/38250/3546 27>. Acesso em: 25 jul. 2018. 